\title{
Los cambios de la educación a nivel tecnológico frente a la pandemia
}

El contexto educativo se ha constituido en uno de los entornos más afectados debido a la pandemia del COVID-19, por cuanto ha tenido que ajustarse a las transformaciones imprevistas que se suscitaron a raíz del cierre de sus puertas en el ámbito físico. Para responder a este cambio repentino, tanto el personal directivo como los docentes y estudiantes tuvieron que reingeniarse y continuar con el proceso formativo bajo la modalidad a distancia. Esta aseveración coincide con Sandoval (2020: 3), quien manifiesta lo siguiente: "Ante el aislamiento preventivo obligatorio que acobija a las instituciones escolares, se hace necesario que los educadores implementen el uso de herramientas TIC como estrategia didáctica en el proceso de aprendizaje con los estudiantes". En función de ello, todos tuvieron que acudir a otras alternativas que evitaran la interrupción de las actividades académicas ya en curso. Por tal razón, optaron por el empleo de las Tecnologías de Información y Comunicación, a fin de no perder la secuencia en el abordaje de los contenidos que se estaban impartiendo antes del devenir del confinamiento.

Ahora bien, ¿qué herramientas se emplearon a nivel mundial para propiciar la comunicación? Fueron varias las alternativas que se presentaron; sin embargo, entre ellas cabe destacar el empleo de las herramientas como zoom y google meet, las cuales permitieron la interacción no sólo entre docentes y alumnos sino también entre otros miembros del plantel y los padres de familia. Por otro lado, otros de los recursos de fácil acceso empleados por cada uno de los involucrados lo constituyeron el correo, el whatsapp, el telegram, el facebook, entre otros que, de uno u otro modo, dieron paso a la comunicación tanto síncrona como asíncrona. Asimismo, Arrieta et al en Sandoval (2020:3), expone que entre algunos de los recursos TIC, se pueden mencionar los siguientes: "Videoconferencia, Buscadores, Software especializado, Espacios virtuales de comunicación (foros, debates), correo electrónico, chats y mensajería instantánea, materiales didácticos multimedia (en línea o local), listas de discusión/distribución, pizarra electrónica, Hardware (impresora, escáner, cámara digital, etc.)", los cuales son cónsonos con las herramientas educativas antes especificadas.

De acuerdo con Sandoval (2020: 3), "los educadores con el apoyo tecnológico en el proceso de enseñanza-aprendizaje, están contribuyendo a estimular nuevos procesos de aprendizaje, donde los estudiantes son los actores principales de su proceso de 
formación y aprehensión de los nuevos saberes". Esta afirmación es muy cierta, ya que el estudiante ha sido el protagonista de su propio aprendizaje, asumiendo un rol activo en cada una de las tareas que realiza.

Por todo lo anterior, esta editorial está dedicada a los cambios de la educación a nivel tecnológico frente a la pandemia, por cuanto supone resaltar tanto la trascendencia de las TIC en la educación como el avance que ha experimentado la instrucción, gracias al uso frecuente que, en la actualidad, se ha hecho de las mismas. En tal sentido, uno de los beneficios que estos cambios han propiciado en la educación, ha sido el de integrador de experiencias y aprendizajes, debido a que no sólo los estudiantes han compartido saberes sino también los docentes, los padres e inclusive, la comunidad en general.

Desde esta perspectiva, CIENCIAMATRIA, toma como base esta realidad educativa, a objeto de servir como punto de partida para la indagación profunda de estas experiencias y así brindar al docente las alternativas posibles para enfrentar situaciones como la pandemia 'COVID-19', que, hoy en día, sigue en vigencia y requiere de recursos de apoyo extra en la consecución y no interrupción de los objetivos propuestos dentro del proceso de aprendizaje. Valdría la pena también preguntarse, ¿qué otras vías de solución hay para los países poco dotados de tecnología? Sería un tema para la reflexión, aunado a las estrategias que debe implementar cada institución gubernamental para sus ajustes a los cambios. Además constituye un tema de interés general, debido a que la integración y convenios entre países podrían contribuir a impulsar el empleo de estas estrategias en los países con poca cultura o recursos TIC.

\section{QDra. Garlina Qleonor Gaxcía Obento}

academico@iieakoinonia.org

Instituto de Investigación y Estudios Avanzados Koinonía

Venezuela

https://orcid.org/0000-0002-3497-9187 